\title{
EFFECT OF STABILIZING TREATMENT ON PRECIPITATION BEHAVIOR OF ALLOY 706
}

\author{
Takashi Shibata*, Yukoh Shudo*, Tatsuya Takahashi**, Yuichi Yoshino*, and Tohru Ishiguro** \\ *Technology Research Center, The Japan Steel Works, Ltd., \\ 1-3 Takanodai, Yotsukaido, Chiba 284, Japan \\ **Muroran Research Laboratory, The Japan Steel Works, Ltd., \\ 4 Chatsu-machi, Muroran, Hokkaido 051, Japan
}

\begin{abstract}
Ni-Fe-base superalloy 706 has recently been used for high temperature services. A stabilizing treatment between solution-annealing and agehardening treatments has been proposed for this alloy to improve its creep rupture life. However, the relationship between stabilizing treatment and precipitation behavior has not been well understood. The precipitation behavior of Alloy 706 was investigated and related with creep rupture properties. Samples taken from a gas turbine disk forging were solution-treated at $980^{\circ} \mathrm{C}$ for $3 \mathrm{~h}$ and stabilizing-treated in a range of 780 to $900^{\circ} \mathrm{C}$ for $1.5 \mathrm{~h}$, followed by the double-aging at $720^{\circ} \mathrm{C}$ for $8 \mathrm{~h}$ and at $620^{\circ} \mathrm{C}$ for $8 \mathrm{~h}$. Precipitation behavior of these samples was examined by TEM, and creep rupture tests were conducted at three conditions with varying temperature and applied stress.
\end{abstract}

Fine $\gamma^{\prime}-\gamma^{\prime \prime}$ co-precipitates having the core of $\gamma^{\prime}$ being overlayed with $\gamma^{\prime \prime}$ on its top and/or bottom and large $\gamma^{\prime}-\gamma^{\prime \prime}$ co-precipitate having the

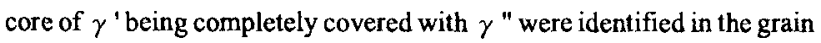
matrix together with large $\gamma^{\prime}$ and fine $\gamma^{\prime \prime}$ phases that have been found to precipitate in Alloy 706. $\eta$ was identified at the grain boundary and found to be accompanied with a serrated grain boundary and denuded zone. Such precipitation behavior was significantly affected by stabilizing temperature, especially below $840^{\circ} \mathrm{C}$, and so was creep rupture property accordingly. It is concluded that the best creep rupture properties are obtained when an optimum combination is established between intra-

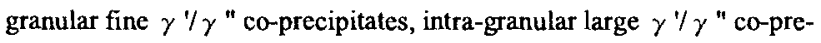
cipitates, and the inter-granular $\eta$ phase.

\section{Introduction}

$\mathrm{Ni}-\mathrm{Fe}$-base superalloys are age-hardened by the precipitation of coherent $\gamma^{\prime}$ and/or $\gamma^{\prime \prime}$ in the austenitic matrix $\gamma$ (1). Alloy 706 is a relatively new material and was developed from Alloy 718 a representative wrought superalloy. Compared with Alloy 718 , Alloy 706 has a chemical composition of no molybdenum, reduced niobium, aluminum, chromium, nickel and carbon, and increased titanium and iron. This excellent balance of chemical composition results in superior characteristics to Alloy 718 in segregation tendency, hot workability and machinability (24). Therefore, Alloy 706 is suitable for large forgings and has been used for high temperature services (5)

A stabilizing treatment between solution-annealing and age-hardening treatments has been proposed for Alloy 706 to improve its creep rupture life (6). The improvement in creep properties is attributed to the precipitation at grain boundary during the stabiling treatment $(2-4,7-9)$. Wc previously reported elsewhere that creep rupture properties of Alloy 706 were significantly affected by stabilizing treatment temperature (10). However, the relationship between stabilizing treatment and precipitation behavior has not been well understood. The present study is concerned with the stabilizing treatment in an effort to correlate creep rupture properties to the morphlogy of the precipitates that form during the heat treatment.

\section{Procedure}

\section{Material}

The experimental material was taken from a forged gas turbine disk manufactured frome a vacuum induction melted (VIM) and electro slag remelted (ESR) ingot that was diffusion treated and subsequently forged. The material was sectioned mechanically into samples of suitable sizes for the following experiments. The alloy composition used in this study are given in Talbe I.

Table I Chemical Composition of Alloy 706

\begin{tabular}{ccccccccccccccc}
\hline $\mathrm{Ni}$ & $\mathrm{Fe}$ & $\mathrm{Cr}$ & $\mathrm{Al}$ & $\mathrm{Ti}$ & $\mathrm{Nb}$ & $\mathrm{B}$ & $\mathrm{C}$ & $\mathrm{N}$ & $\mathrm{Si}$ & $\mathrm{Mn}$ & $\mathrm{P}$ & $\mathrm{S}$ \\
\hline 42.0 & 37.1 & 15.65 & 0.26 & 1.54 & 2.96 & 0.0034 & 0.008 & 0.0046 & 0.05 & 0.02 & $<0.003<0.0005$ \\
\hline
\end{tabular}




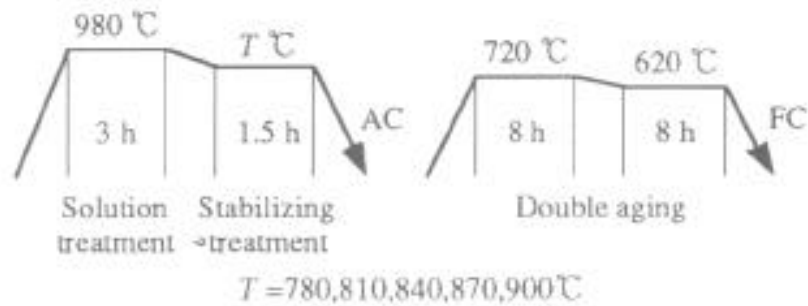

Figure 1: Heat treatment program and conditions.

\section{Heat Treatment}

Heat treatment conditions are shown in Figure 1. The samples were solution-treated at $980^{\circ} \mathrm{C}$ for $3 \mathrm{~h}$ and then stabilizing-treated in a range of 750 to $900 \mathrm{C}$ for $1.5 \mathrm{~h}$. Subsequently they were double-aged at $720^{\circ} \mathrm{C}$ for $8 \mathrm{~h}$ and at $620^{\circ} \mathrm{C}$ for $8 \mathrm{~h}$. Alloy 706 is usually reheated to the stabilizing tem. perature after solution annealing (6). In this study, the stabilizing treatment was conducted in the cooling stage from the solution treatment without cooling the material to the room temperature from the point view of industrial advantage.

\section{Microscopy}

These samples were examined by scanning electron microscopy (SEM) and transmission electron microscopy (TEM) for their precipitation behavior. Thin film method was used for TEM sample preparation, and final thinning was achieved by electro-polishing. A $200 \mathrm{kV}$ TEM was used with micro-beam techrtique in both electron diffraction and energy disperssive X-ray spectroscopy (EDS), with the probe diameter being minimum Inm.

\section{Creep Rupture Test}

Creep tests were conducted at three conditions : $600^{\circ} \mathrm{C} / 686.5 \mathrm{MPa}, 600$ C $/ 745.3 \mathrm{MPa}$ and $650 \mathrm{C} / 686,5 \mathrm{MPa}$. The diameter of specimens was $6 \mathrm{~mm}$ and the gauge length was $30 \mathrm{~mm}$. In order to ensure the uniformity of temperature, the specimens were held for $24 \mathrm{~h}$ at the test temperatures before loading.

\section{Results}

\section{SEM Observation}

SEM micrographs of Alloy 706 stabilized at various temperatures and aged are shown in Figure 2. No precipitate was seen inside the grains or at the grain boundary for the samples stabilized at 900 and $870 \mathrm{C}$ as for the un-stabilized one. On the contrary, many precipitates were observed when the stabilizing temperature was below $840^{\circ} \mathrm{C}$. Especially cellular precipitates that lay parallel to each other were observed clearly at the grain boundary,

\section{Intra-granular Precipitate}

In order to identify these precipitates that can not by SEM. TEM observation was conducted. It is reported that the intra-granular precipitate is either $\gamma^{\prime}(2,3,7,8)$ or $\gamma^{\prime \prime}(9,10)$ and that they form simultaneously $(4,11,12)$. Therefore, TEM observation was directed to the grain interiof.

T7EM image of Alloy 706 stabilized at $810^{\circ} \mathrm{C}$ and aged is shown in Figure 3, where all types of precipitates identified in this study are seen. The precipilates of various shapes and sizes exist inside the grain. The spots arising from long-tange ordering were clearly observed in a selected area
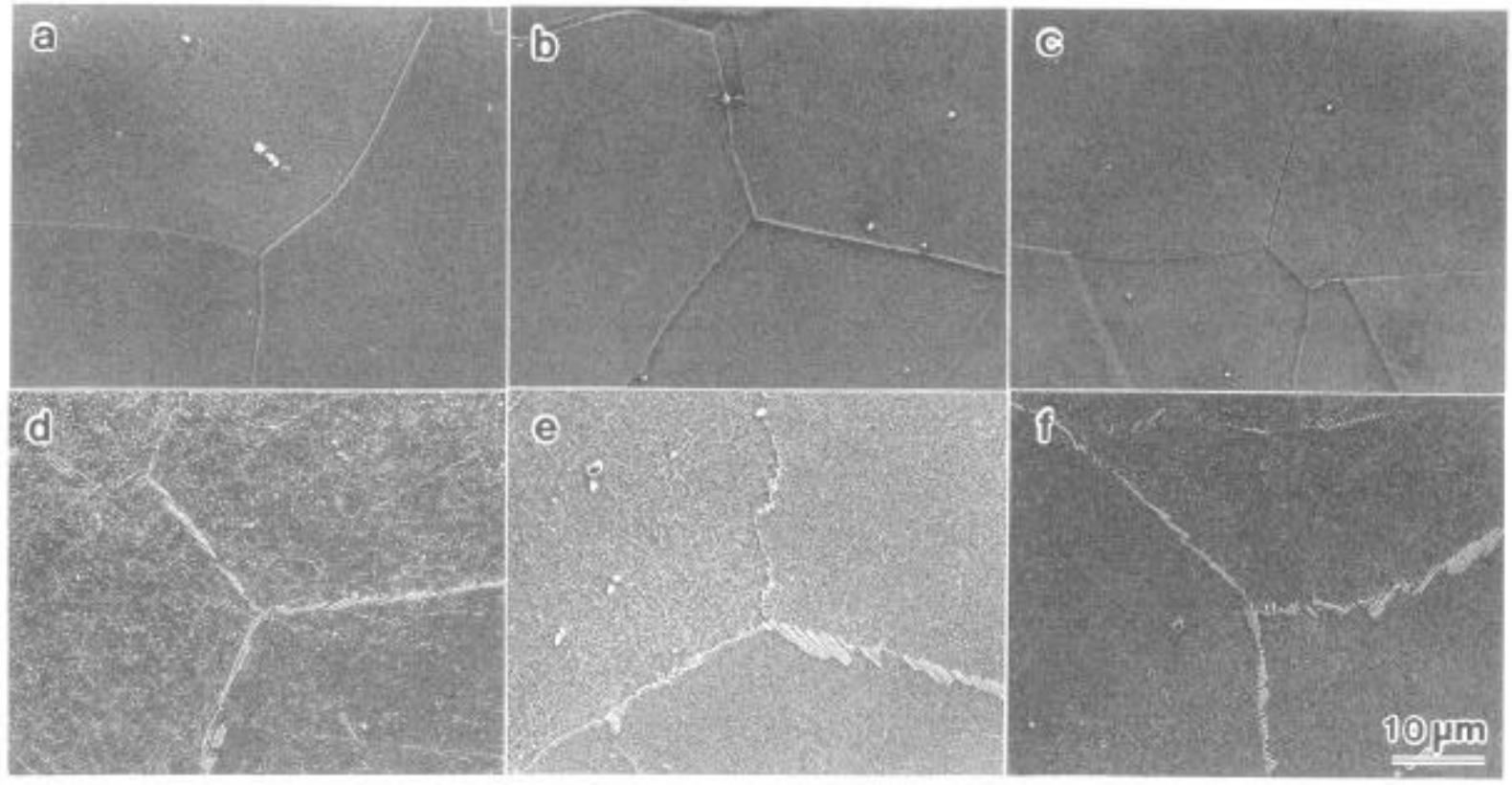

Figure 2 : SEM mierographs of Alloy 706 aged following by the stabilizing treatment at various temperatures : (a) unstabilized, (b) $900^{\circ} \mathrm{C}$, (c) $870^{\circ} \mathrm{C}$, (d) $840^{\circ} \mathrm{C}$, (e) $810^{\circ} \mathrm{C}$ and (f) $780^{\circ} \mathrm{C}$. 

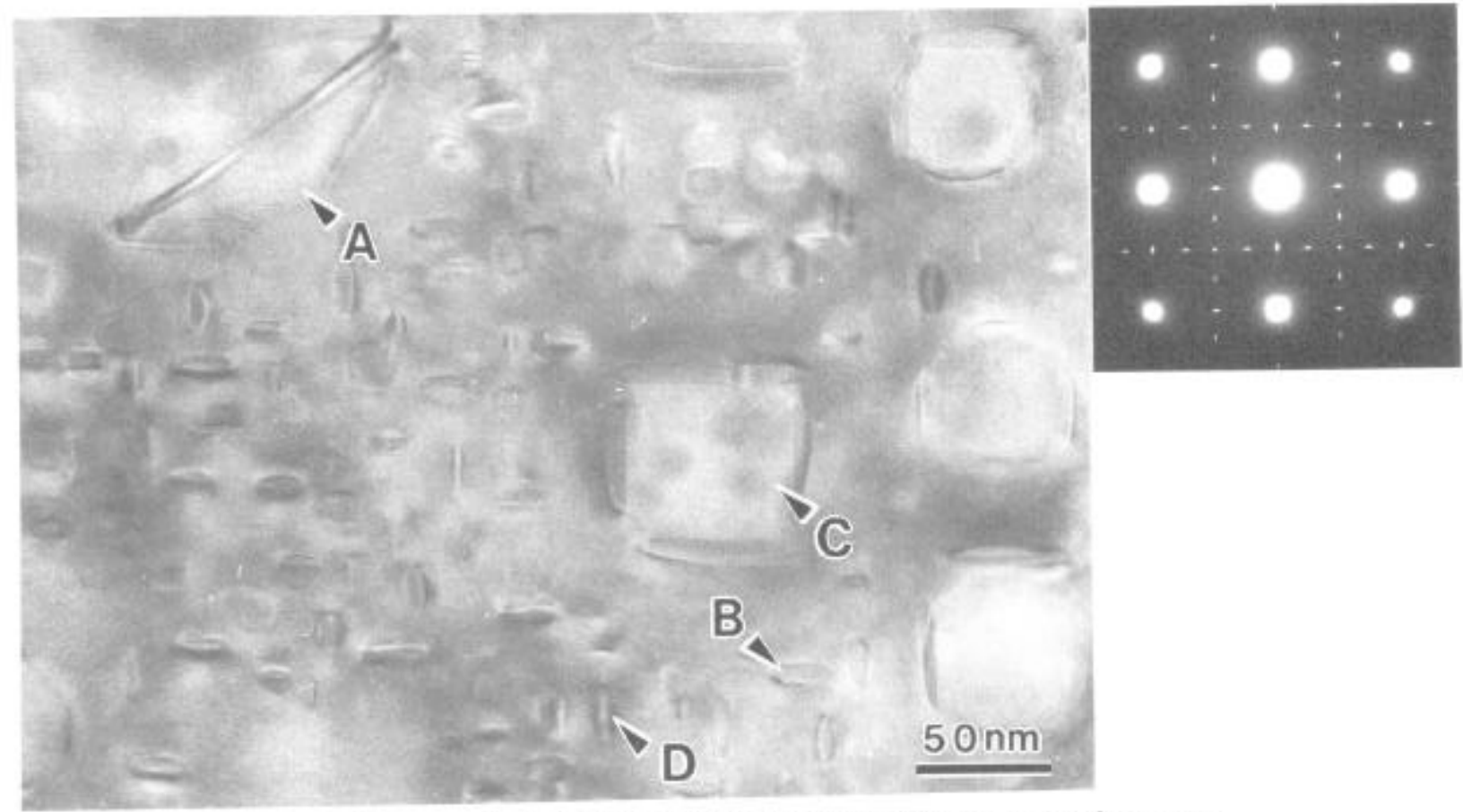

Figure 3 : TEM micrograph and selected area diffraction of Alloy 706 stabilized at $810^{\circ} \mathrm{C}$ and aged.

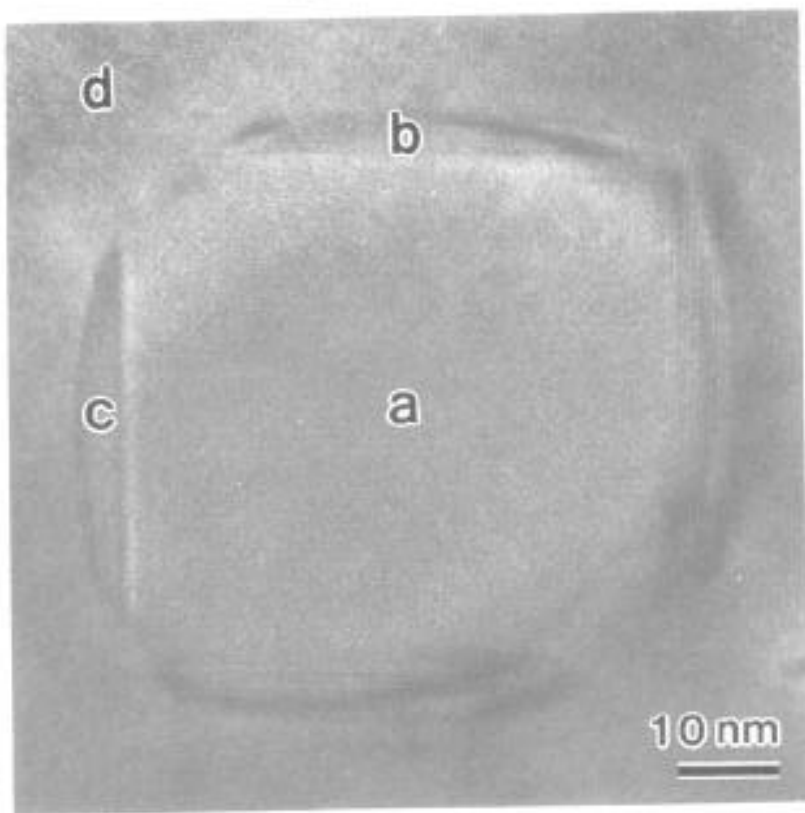

Figure 4 : High resolution image of the cuboidal $y$ "- $y$ "co-precipitate in Alloy 706 stabilized at $810 \mathrm{C}$ and aged.

diffraction pattern given in Figure 3, indicating the presencec of $\gamma$ ' andjor $y^{*}$. Therefore, high resolution observation was made together with micro-beam techniques in order to identify cach precipitate.

As a result, four types of precipitates were identified in the grain interior. The relatively large precipitates as indicated by arrow $\mathrm{A}$ were identified $y^{\prime}$, there size being several hundred nanometers. The fine precipitates as indicated by arrow B were identified $y$ ", there size being several nanometers. The precipitates as indicated by arrows $C$ and D were identified

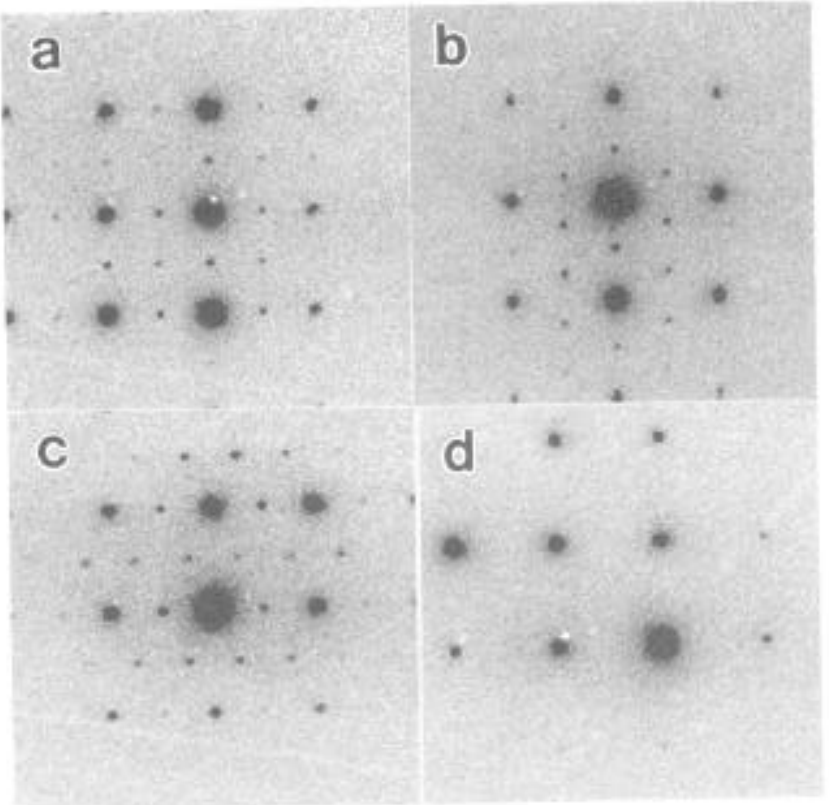

Figure 5 : Micro beam diffraction patterns al the location shown in Figure 4 .

two types of $\gamma^{4}-\gamma^{*}$ co-precipitates which had not yet been reported with Alloy 706 .

A high resolution image, micro-beam electron diffraction patterns and micro-bcam EDS spectra are shown in Figure 4, 5 and 6, respectively, of the co-precipitates as indicated by arrow $C$. They indicate that this large cuboidal co-precipitate has the core of Ti rich $\gamma$ ' being completely cov. ered with the Nb rich $\gamma$ " thin skin, refferred to by R.Cozar and A.Pineau as co-preciputate of "compact morphlogy" in the modified 718 alloys (13- 

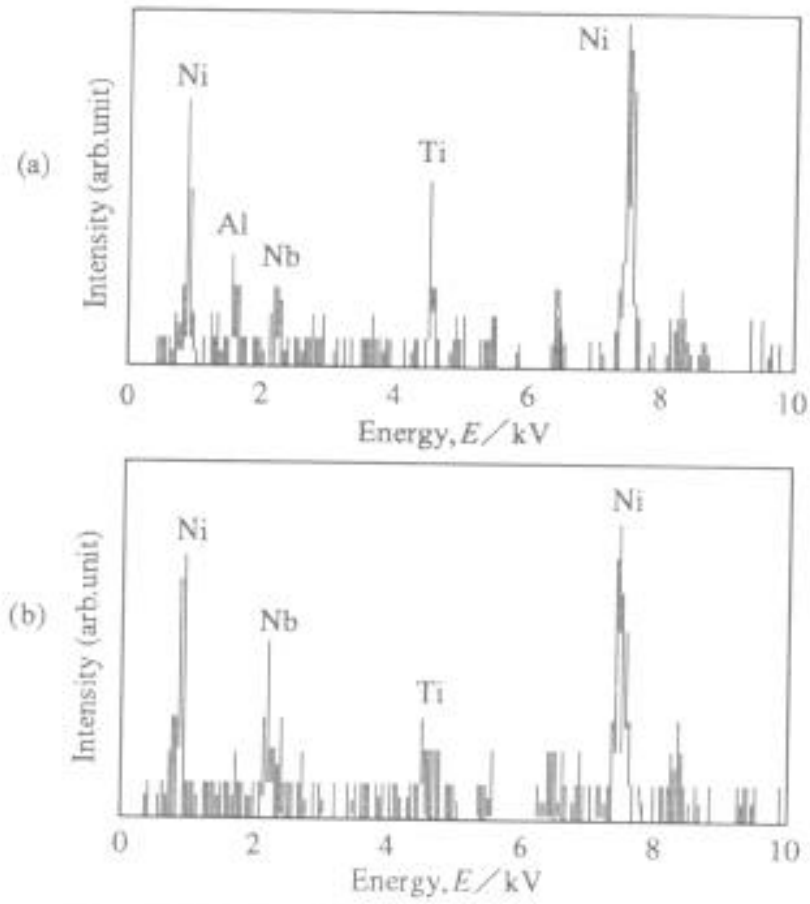

Figure 6: Micro beam EDS spectra at the focations shown in Figure 4 .
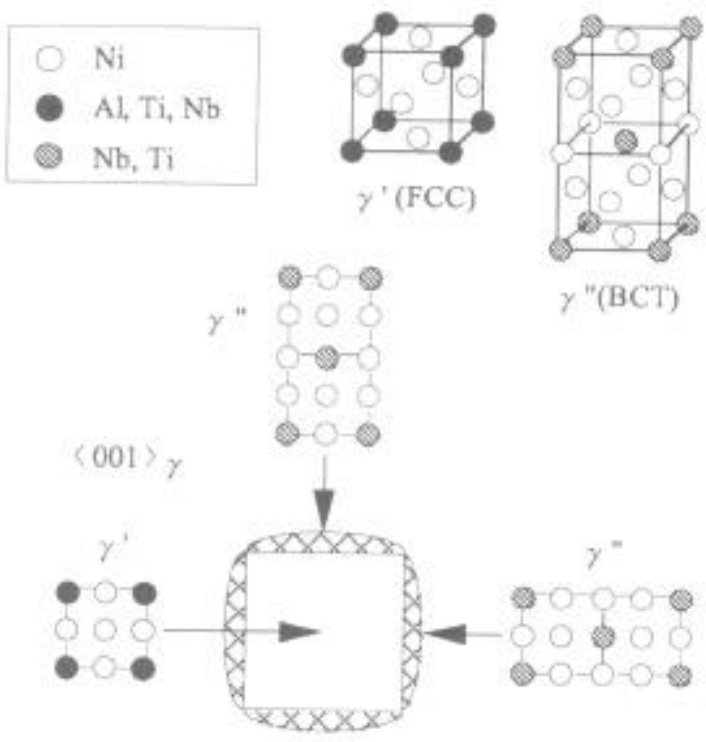

Figure 7 ; Schematic diagram of the cuboidal $\gamma^{*}-\gamma^{\prime \prime}$ co-precipitate in Alloy 706

20). The coherency between $\gamma, y^{\prime}$ and $\gamma^{\prime \prime}$ is maintained as schematically illustrated in Fugure 7. It is reported that this co-precipitate is obtained at a higher $(\mathrm{Ti}+\mathrm{Al}) / \mathrm{Nb}$ ratio than in regular Alloy 718. In fact, this ratio is greater of Alloy 706 than of Alloy 718 . However, the chemical composition of Alloy 706 is out of the co-precipitate range of the S-Rdiagram for Alloy $718(13,14)$. The co-precipitate range may be shifted for Alloy 706. Further study is needed in this respect.

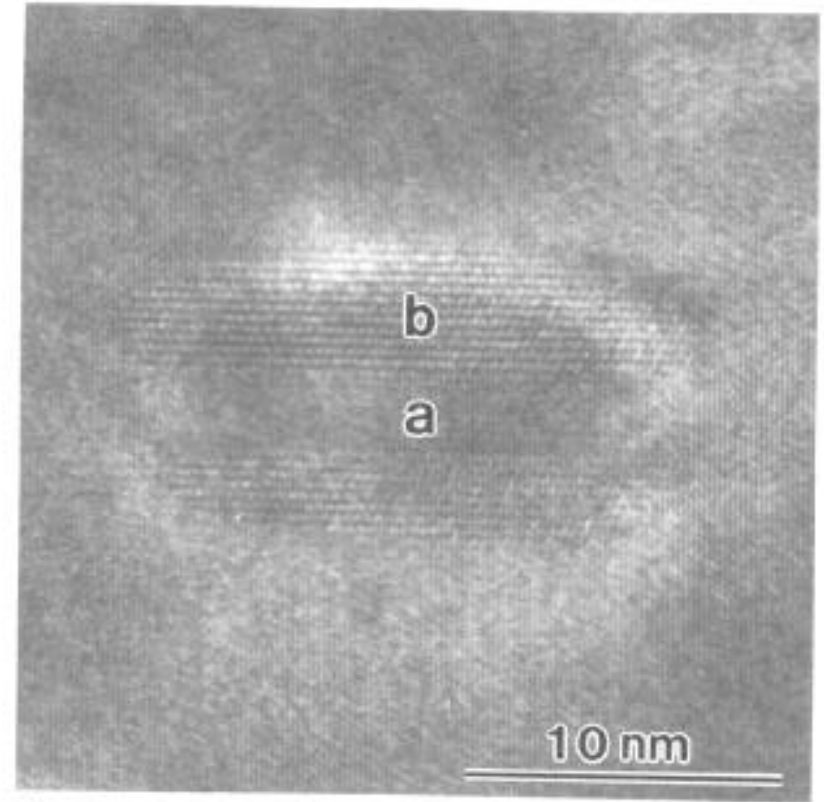

Figure 8: High resolution image of the overlayed $\gamma^{\prime}-\gamma^{\prime \prime}$ co-precipitate in Alloy 706 stabilized at $810^{\circ} \mathrm{C}$ and aged.
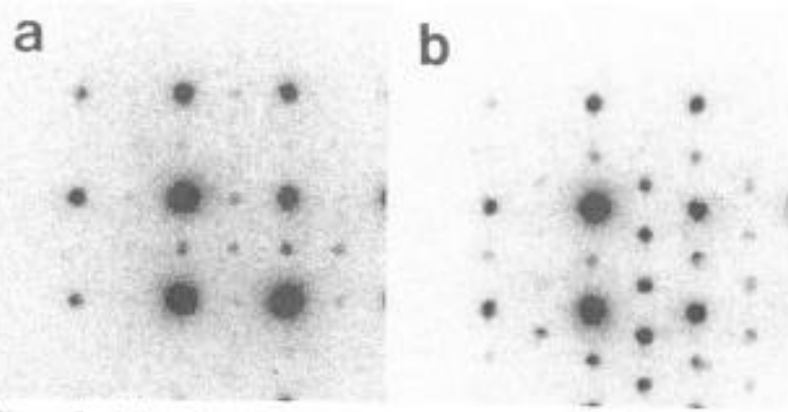

Figure 9 : Micro beam diffraction patterns at the locations shown in Figure 8.

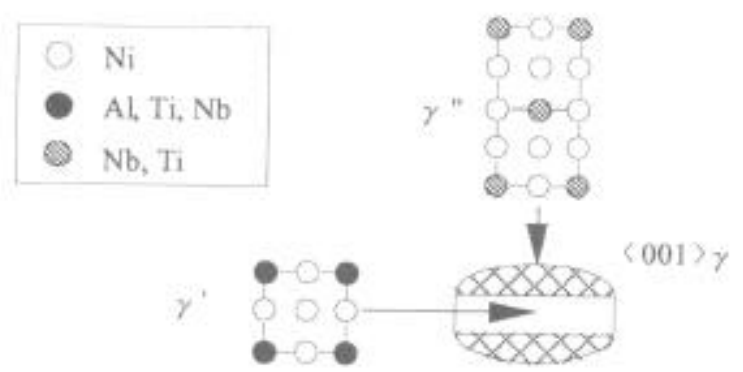

Figure 10 : Schematic diagram of the overlayed $\gamma^{4}-\gamma^{\text {" co-precipitate }}$ in Alloy 706

TEM information of the co-precipitates as indicated by arrow D are shown in Figure 8 and 9, respectively. Although it is too small to determine precisely its shape and inner strueture, it appears to be either a disk or an ellipsoid. From both figures, this fine precipitate has the core of $\gamma$ ' being overlayed with $\gamma^{*}$ on its top and/or bottom, refferred to by R.Cozar and A.Pincau as co-precipitate of "non-compact morphlogy", again (13-20), The coherency between $\gamma, \gamma^{\prime}$ and $\gamma^{\prime \prime}$ is maintained as schematically illustrated in Figure 10. 

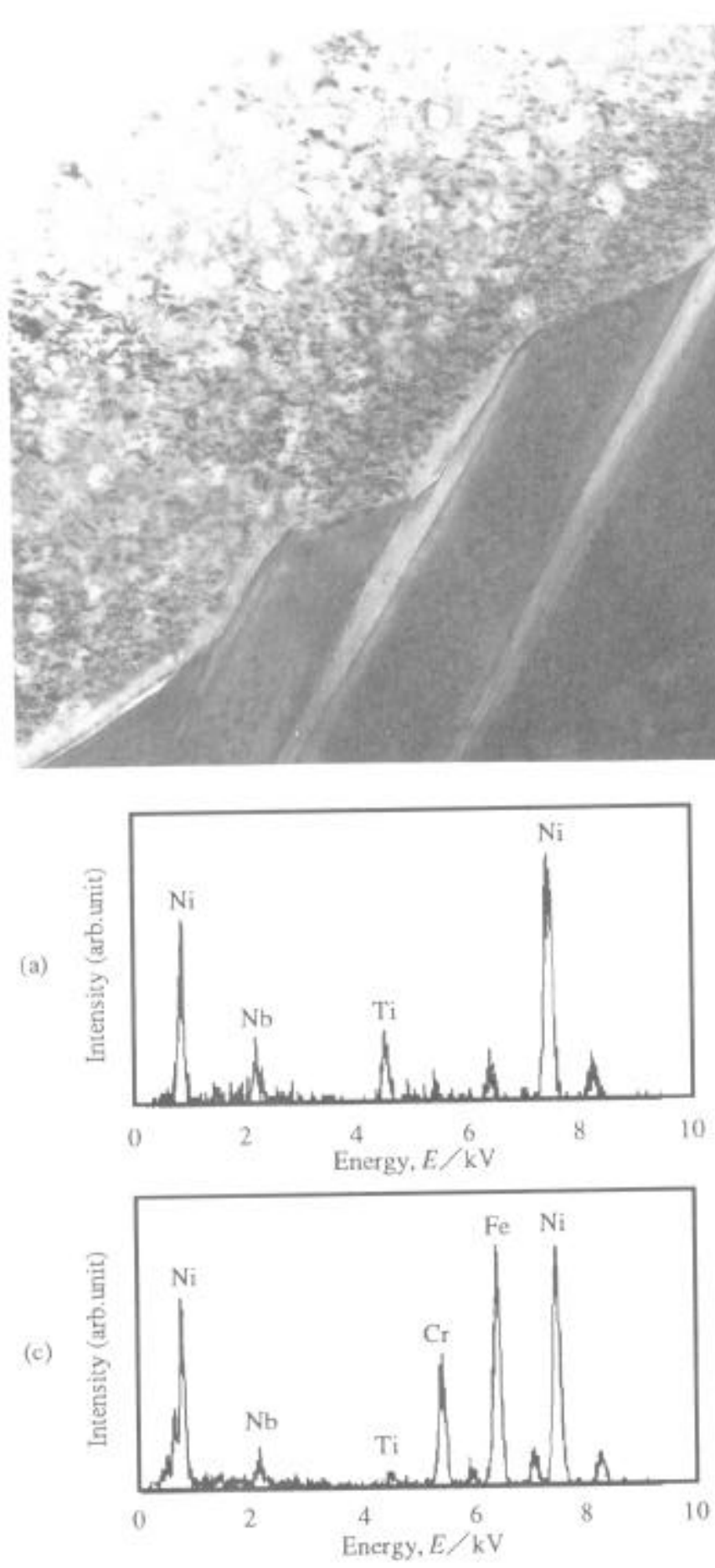

Inter-granular Precipitate

Figure 11 shows TEM image of the cellular precipitates at the grain boundary of Alloy 706 stabilized at $810^{\circ} \mathrm{C}$ and aged. These phases were identified $\eta$ from the results of micro-beam electron diffraction and micro-beam EDS. These precipitates have a specific orientation relationship with the $\gamma$ matrix; $[011], \not /[2 \pi 0]$, and $\{11 \overline{1}\}, / /\{0001\}$, This relationship is consistent with the study reported by other (9), indicating a semi-coterency between $\eta$ and $y$. The cellular $\eta$ appears parallel to

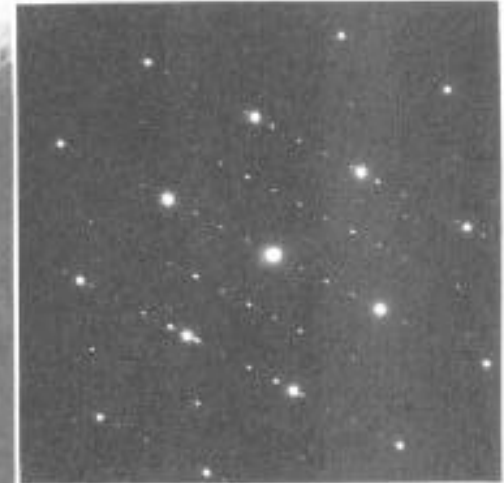

Figure 11 : TEM micrograph and selected area diffraction pattern of grain boundary in Alloy 706 stabilized at $810^{\circ} \mathrm{C}$ and aged.

\section{0nm}

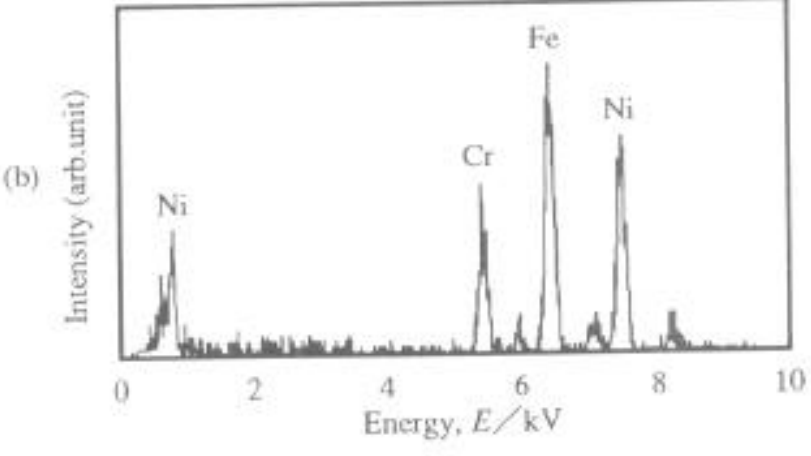

Figure 12 : EDS spectra at (a) $\eta$, (b) denuded zone and (c) the matrix. each other in order to meet this orientation relationship.

As shown in Figure 11, the precipitation of $\eta$ resulted in the formation of the serrated grain boundary and denuded-zone around it. Micro-beam EDS found a leanness of Niobium and Titanium in this zone as shown in Figure 12. The denuded zone was obscure after $840^{\circ} \mathrm{C}$ stabilization, but it became wider and more distinct as the stabilizing temperature decreased. At $780 \mathrm{C}$, its width was greater than 100nm as shown in Figure 13. 


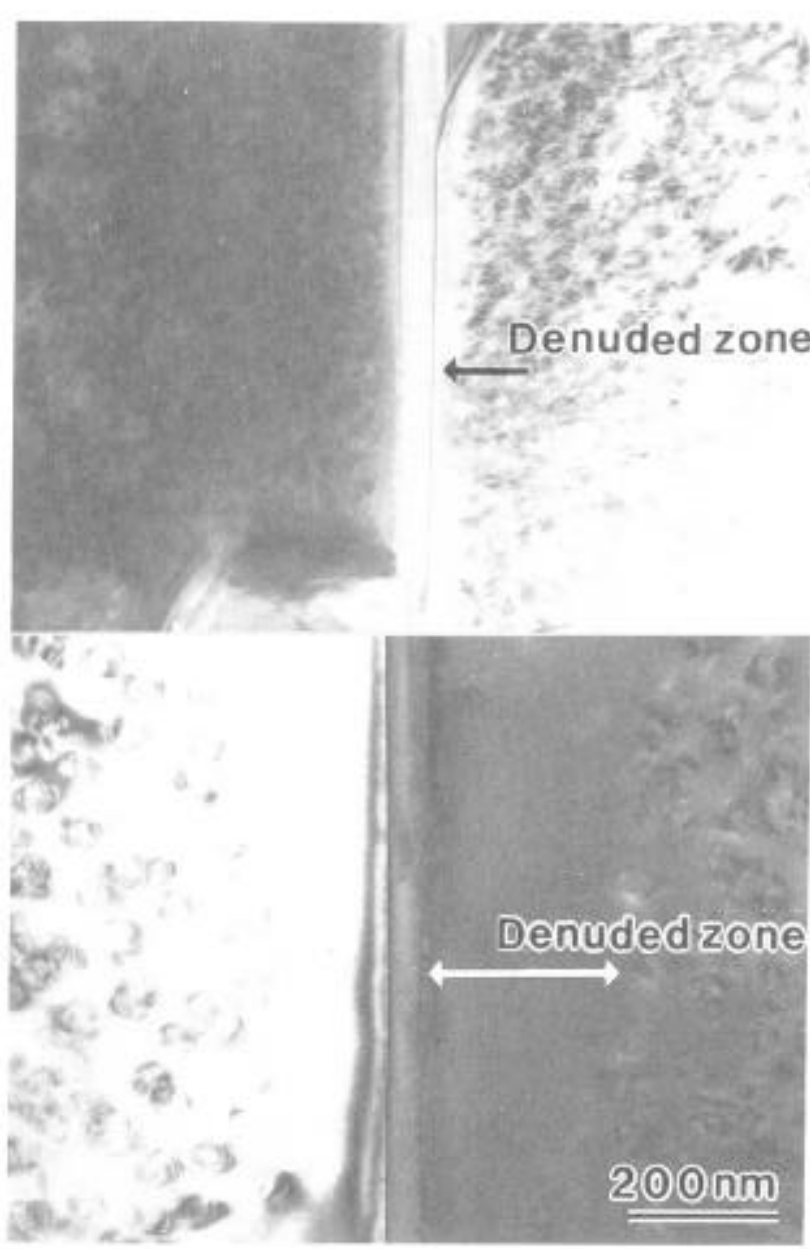

Figure 13 : TEM micrograph near the grain boundary of Alloy 706 aged afler stabilizing at (a) $810^{\circ} \mathrm{C}$ and (b) $780^{\circ} \mathrm{C}$,

It is reported that there is not only $\eta$, but also $\delta$ at the grain boundary at Alloy $706(7,9,12)$. However, no precipitate was identified $\delta$ for more than a hundred precipitates at grain boundary in this study. Only a few precipitates were identified $\gamma^{\prime}$ in the samples stabilized at 840 and 810 C. This is thought that $\eta$ forms through the transformation of $\gamma \rightarrow \gamma$ ' $\rightarrow \eta$ as in A286 (1), leaving $\gamma^{\prime}$ as an intermediate phase. The grain boundary appears to become serrated as the $\eta$ phase grows.

\section{Precipitation Behavior and Stabilizing Temperature}

In order to clarify at which stage of the whole heat treatment such precipitation as described above occurs, TEM studies were carried out for the samples before and after the aging treatment, The relatively large $y^{\text {' }}$ and cuboidal $\gamma^{\prime}-\gamma^{\prime \prime}$ co-precipitate were found to form in the stabilizing treatment at 840,810 and $780^{\circ} \mathrm{C}$. The precipitation of $\eta$ and the accompanying phenomena were also found to occur in the same stabilizing treatment. On the contrary, the fine $\gamma^{\prime \prime}$ and overlayed $\gamma^{\prime}-\gamma^{\prime}$ co-precipitate formed during the double-aging treatment. But, when stabilized at $780^{\circ} \mathrm{C}$, these fine precipitates were rarely observed even after aging, It is extremely difficult to determine the amount of these fine precipitates, especially the co-precipitate. From Figure 14, however, the amount of the fine precipitates formed at the aging treatment are grater as the stabilizing temperature higher, It is concluded that the cuboidal co-precipitale is dominant when stabilized at $780^{\circ} \mathrm{C}$ whereas the fine precipitates are when the stabilizing temperature is higher than $810 \mathrm{C}$.

The results obtained in this study has led to three groups of stabilizing temperatures in terms of the precipitation behavior ; 900 and $870 \mathrm{C}$ (Group A), 840 and $810^{\circ} \mathrm{C}$ (Group B), and $780^{\circ} \mathrm{C}$ (Group C). The precipitation belavior of Group $\mathrm{A}$ is virtually the same as in the case where the stabilizing treatment is discarded. That is, the fine $\gamma$ " and overlayed $\gamma$ " $-\gamma$ " co-precipitate arise inside the grain without any precipitation at the grain boundary. In the case of Group B, the fine precipitates are still dominant whereas the large cuboidal $\gamma^{\prime}-\gamma^{\prime \prime}$ co-precipitate is also present inside the grain. At the same time, the \#) phase grows at the grain boundary, resulting in the grain boundary serration and the denuded zone that is still limited and narrow with this group. The large cuboidal coprecipitate is dominant in Group $\mathrm{C}$, and the denuded zone becomes very wide. The precipitation behavior described here is summarized in Table II.

\section{Creep Rupture Property and Stabilized Temperature}

The creep strain vs. time curves for three test conditions are shown in Figure 15,16 and $17,600 \mathrm{C} / 686.5 \mathrm{MPa}, 600 \mathrm{C} / 745,3 \mathrm{MPa}$ and $650 \mathrm{C} /$ $686.5 \mathrm{MPa}$, respectively. The creep rupture properties can be grouped into three classes ; here again Group A (900 and $\left.870^{\circ} \mathrm{C}\right)$, Group B (840 and $810^{\circ} \mathrm{C}$ ) and Group $\mathrm{C}\left(780^{\circ} \mathrm{C}\right)$. The crecp rupture property does not appear to be affected by the stabilizing treatment for Group A. However, it was significantly affected when stabilizing temperature is below 840 C. The creep rupture property of Group B are markedly improved in creep rupture life and creep nupture elongation. On the contrary, it was much degraded in the Group C.

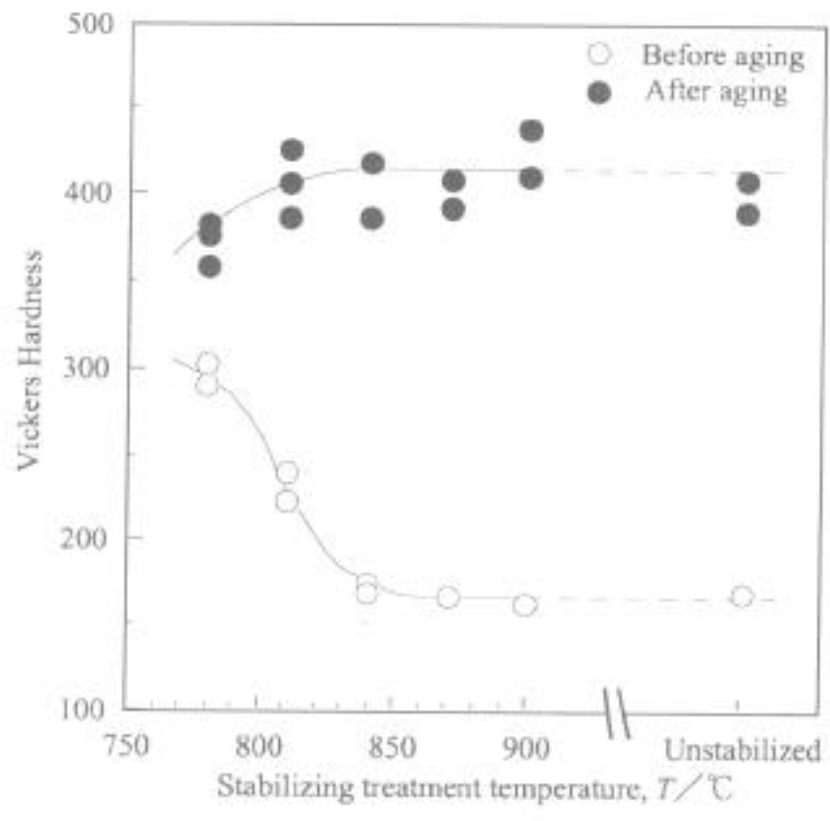

Figure 14: Change in vickers hardness with the stabilizing treatment of Alloy 706 . 
Table II Summary Of Precipitation Behavior For Alloy 706 Stabilized At Various Temperatures ( $O$ : pronounced $\triangle$ : observable $X:$ absent )

\begin{tabular}{|c|c|c|c|c|c|c|}
\hline $\begin{array}{l}\text { stabilizing } \\
\text { temperature }\end{array}$ & $\begin{array}{c}\text { large } \\
\gamma^{\prime}\end{array}$ & $\begin{array}{r}\text { fine } \\
\gamma^{\prime \prime}\end{array}$ & $\begin{array}{c}\text { fine overlayed } \\
\gamma^{\prime}-\gamma^{\prime \prime}\end{array}$ & $\begin{array}{c}\text { large cuboiral } \\
y^{\prime}-y^{\prime \prime}\end{array}$ & $\eta$ & denuded zone \\
\hline Unstabilized & $x$ & 0 & 0 & $x$ & $x$ & $x$ \\
\hline $900^{\circ} \mathrm{C}$ & $x$ & 0 & 0 & $x$ & $x$ & $x$ \\
\hline $870^{\circ} \mathrm{C}$ & $x$ & 0 & 0 & $x$ & $x$ & $x$ \\
\hline $840^{\circ} \mathrm{C}$ & 0 & 0 & 0 & $\triangle$ & 0 & $\Delta$ \\
\hline $810^{\circ} \mathrm{C}$ & $\triangle$ & 0 & 0 & $\Delta$ & 0 & $\triangle$ \\
\hline $780^{\circ} \mathrm{C}$ & $\triangle$ & $\triangle$ & $\Delta$ & 0 & 0 & 0 \\
\hline
\end{tabular}

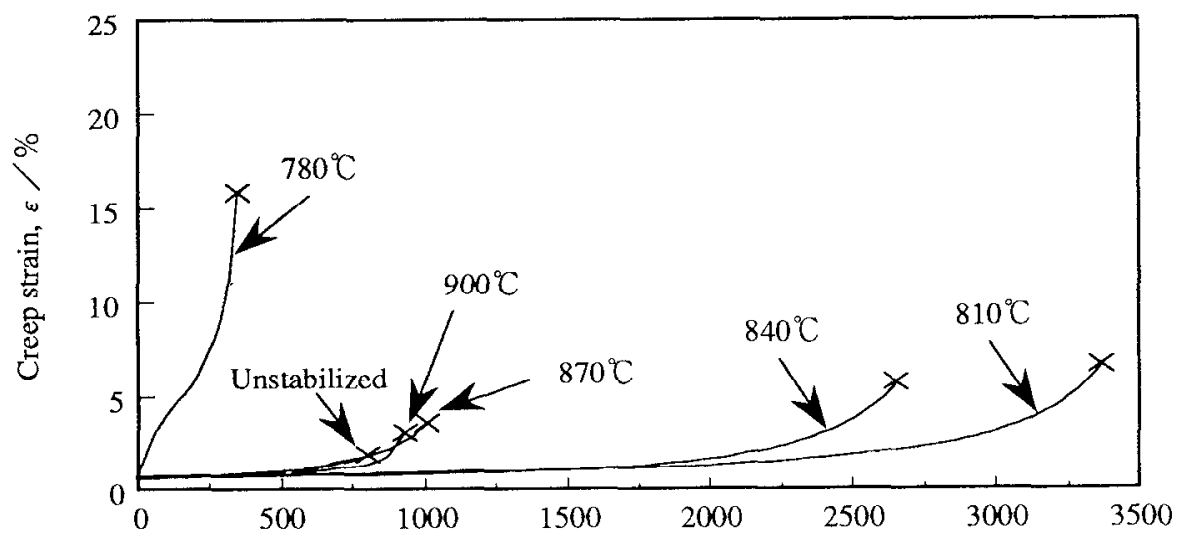

Figure 15 : Creep rupture curves of Alloy 706 tested at $600^{\circ} \mathrm{C} / 686.5 \mathrm{MPa}$.

'Time, $t / \mathrm{h}$

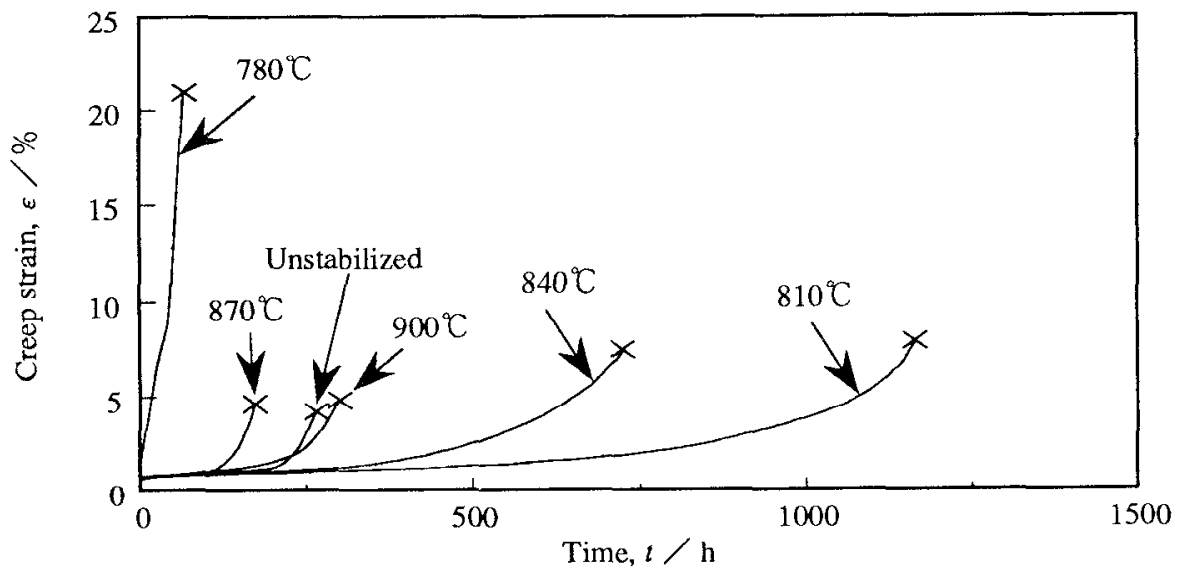

Figure 16: Creep rupture curves of Alloy 706 tested at $600^{\circ} \mathrm{C} / 745.3 \mathrm{MPa}$.

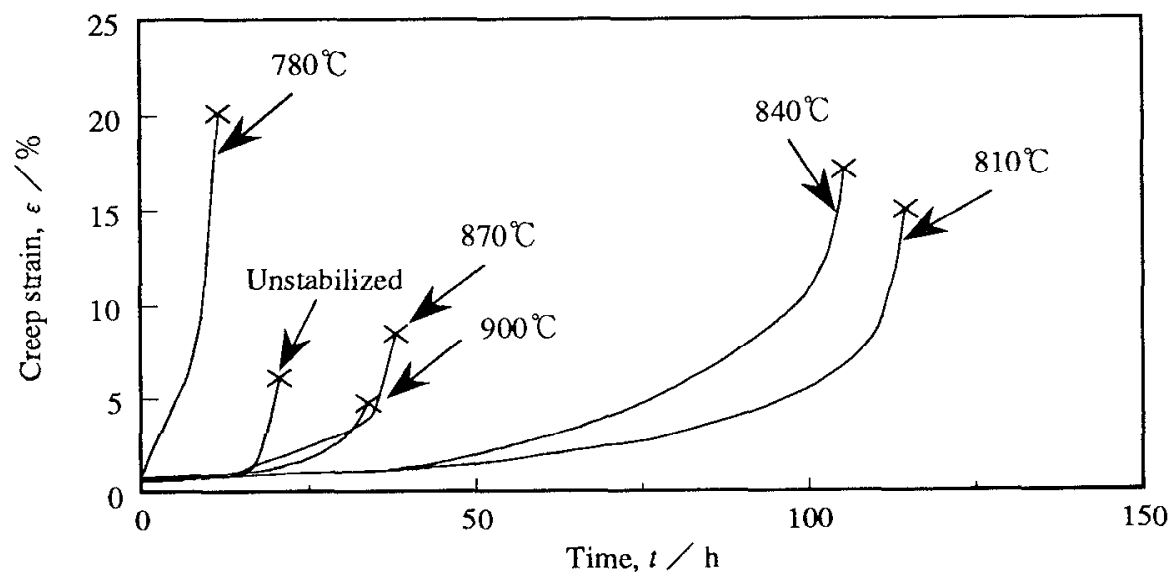

Figure 17: Creep rupture curves of Alloy 706 tested at $650^{\circ} \mathrm{C} / 745.3 \mathrm{MPa}$ 


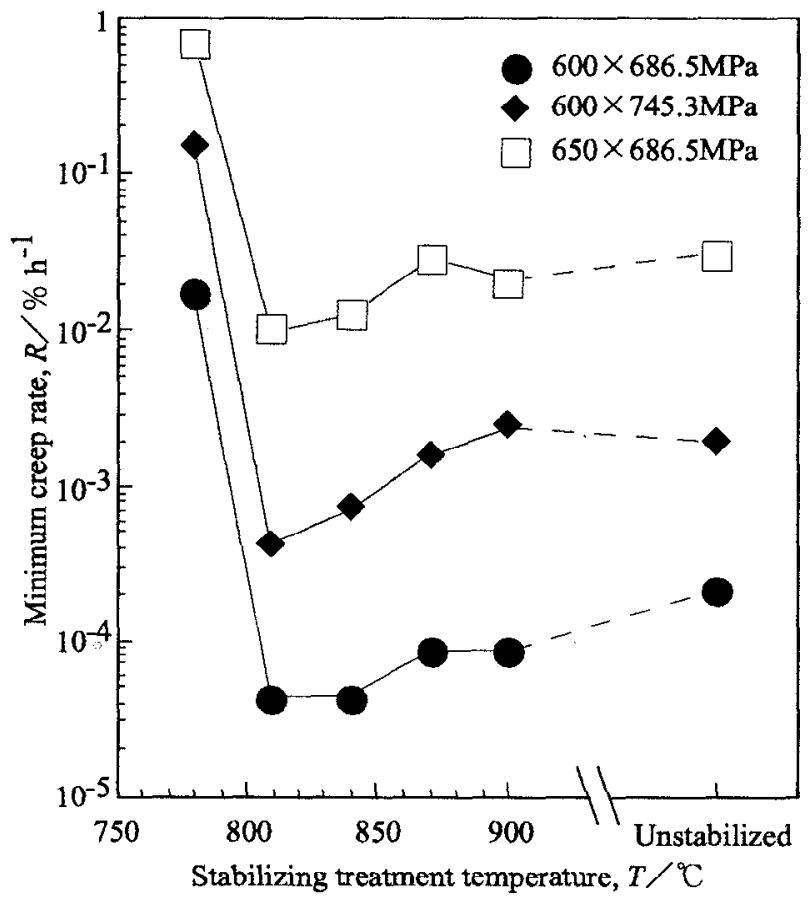

Figure 18: Change in the minimum creep rate of Alloy 706 with stabilizing temperature.

\section{Discussion}

As described, the classification of precipitation behavior agrees well with the classification of creep rupture properties, indicating a strong connection between them. Therefore, the results of the present study are discussed here in accordance with the classification of stabilizing temperature.

\section{Group A; stabilized at 900 and $870^{\circ} \mathrm{C}$}

The precipitation behavior is virtually the same as for the heat treatment program without stabilizing treatment. Therefore, creep rupture properties are not affected by the stabilizing treatment.

\section{Group B ; stabilized at 840 and $810^{\circ} \mathrm{C}$}

Creep rupture properties are markedly improved. This improvement is contributed by the precipitations in the grain matrix and at the grain boundary.

The contribution of the precipitates in the matrix is depicted in Figure 18 that shows the minimum creep rate replotted from Figure 15, 16 and 17. The minimum creep rate is the smallest in the stabilizing temperature range for Group $B$. In this stabilizing temperaturc range, relatively large cuboidal $\gamma^{\prime}-\gamma^{\prime \prime}$ co-precipitate is found to co-exist with the fine overlayed co-precipitates. It is reported that the cuboidal co-precipitates are more stable than single phase precipitates and are able to improve high temperature properties of Alloy 718 (13-20). The co-precipitates

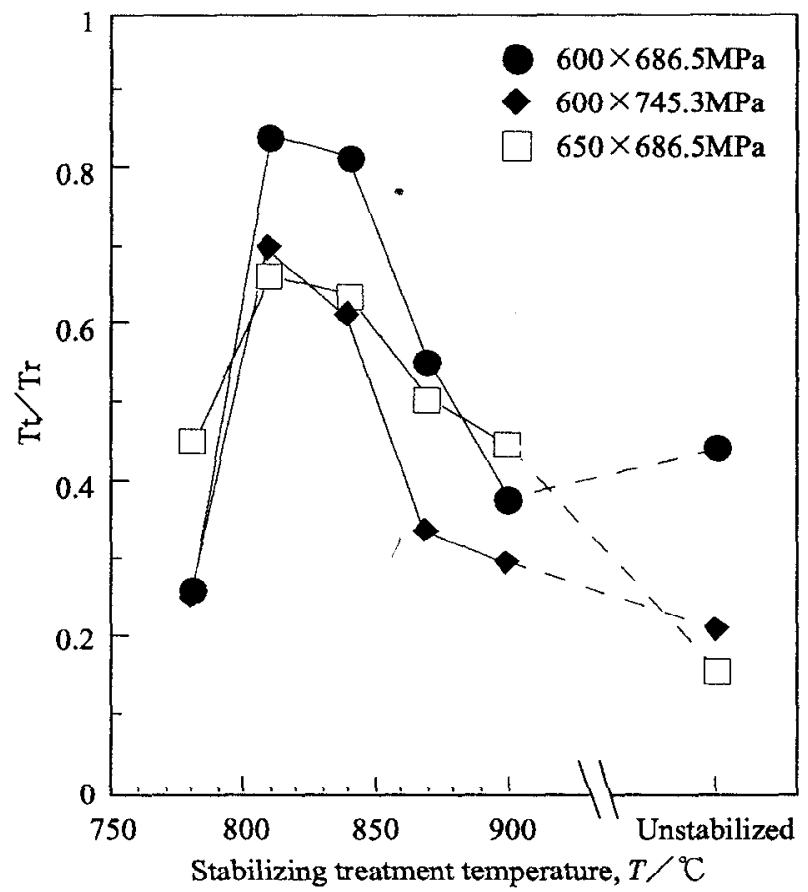

Figure 19 : The relative duration of tertially creep rupture life for Alloy 706 stabilized at different temperatures.

shold have the same effect in Alloy 706. The co-existed condition with large precipitates and fine ones may also contribute to the reinforcement of grain interior.

The contribution of the precipitation at the grain boundary is seen in the relative duration of tertiary creep to the whole creep life shown in Figure 19 that is replotted from Figure 15,16 and 17. The relative tertiary creep duration is the greatest in the stabilizing temperature range of Group B. As seen in Table $I$, this improvement is mainly due to the reinforcement of grain boundary which is caused by the pinning of grain boundary by $\eta$, grain boundary serration, and indistinct denuded zone. Firstly, precipitates at grain boundary prevent effectively the grain boundary sliding. In Alloy 706, $\eta$ phase has semi-coherency with the matrix and therefore effectively pins the grain boundary. Secondly, the grain boundary serration also prevents the grain boundary sliding effectively $(21,22)$. That is, the geometrical change of grain boundary is considered to extend the tertiary creep duration. Thirdly, the indistinct denuded zone is considered to be retard effectively crack propagation as reported with Alloy 718 (23). In fact, this was supported by SEM micrographs of fracture surfaces shown in Figure 20. The fracture surface of Group B specimens consists of many micro-dimples in contrast to the smooth fracture surface of Group A specimens, although grain boundary fracture occurs in both groups.

\section{Group C; stabilized at $780^{\circ} \mathrm{C}$}

Creep rupture properties are extremely degraded in creep rupture life. However, creep rupture elongation is very large. The minimum creep 


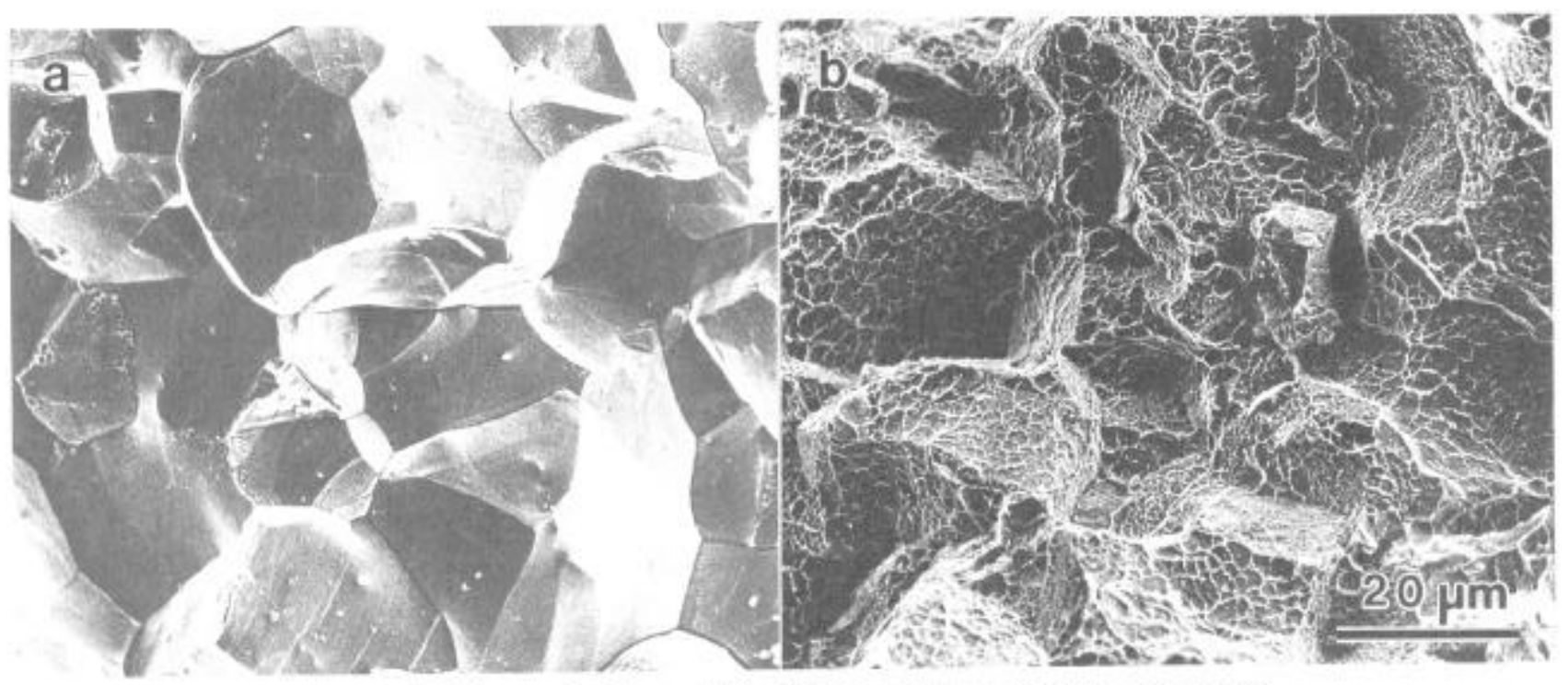

Figure 20 : SEM fractographs of ruptured Alloy $706(\mathrm{a})$ unstabilized and (b) stabilized at $810^{\circ} \mathrm{C}$.

rate is far larger than those of the other groups as seen in Figure 19. The relative tertiary creep duration is smaller than that of Group B as seen in Figure 20. These facts mean that there are two reasons for the degradation of creep propertics.

As seen in Table II, the large cuboidal co-precipitate is dominant inside the grain in this stabilized temperature range. In general, the smaller the precipitates, the more effective they are in precipitation hardening and the more stable they are for heat. Therefore, the degradation of creep properties is attributed to the large precipitates dominant in the matrix. The wide denuded zone around $\eta$ is another characteristic of the precipitation in this temperature range. It causes readily grain boundary sliding whereby overshadowing the beneficial effect of $\eta$ precipitation.

\section{Conclusions}

Intensive TEM study and creep rupture tests were conducted in order to characterize the precipitates and to relate them to creep ruplure properties for Ni-Fe-base superalloy Alloy 706 stabilized at various temperatures. Conclusions are summarized as follows.

(1) The precipitation behavior of Alloy 706 stabilized at $900,870^{\circ} \mathrm{C}$ is pracyically the same as in the case where the stabilizing treatment is discarded. That is, both fine $\gamma^{\text {" and overlayed }} \gamma^{\prime}-\gamma^{\prime}$ " co-precipitate form in the grain matrix at the double-aging treatment, and no precipitation occurs at the grain boundary. Therefore, creep rupture properties is not affected by the stabilizing treatment.

(2) When stabilized at 840 and $810^{\circ} \mathrm{C}$, the fine precipitates are still dominant inside a grain while large cuboidal $\gamma^{\prime}-\gamma^{\prime \prime}$ co-precipitate is present together with them. At the same time, $\eta$ phase precipitates at the grain boundary, causing serrated grain boundaries and narrow denuded zone around $\eta$. The best creep rupture properties are obtained with this complex stage of precipitation.
(3) In the case of Alloy 706 stabilized at $780^{\circ} \mathrm{C}$, large cuboidal co-precipitate is dominant inside the grain, and the denuded zone iss very wide, leading to extremely degraded creep rupture properties.

It can be concluded that the desirable creep rupture properties are obtained when the best combination is achieved for the fine overlayed $\gamma^{\prime \prime}$ $\gamma^{\prime \prime}$ co-precipitates, large cuboidal $\gamma / \gamma$ " co-precipitates, and $\%$ phase.

\section{References}

1. E.E.Brown and D.R.Muzyka, "Nickel-Iron Alloys", Superalloys II. ed., C.T.Sims, N.S.Stoloff, and W.C.Hagel (New York, John Willey \& Sons, 1987), 165-[88.

2. H.L.Eiselstein, "Properties of Inconel Alloy 706", ASM Technical Report, No.C 70-9.5 (1970), 1-21.

3. H.L.Eiselstein, "Properties of a Fabricable, High Strength Superalloy". Metals Enginecring Quarterly. November(1971), 20-25.

4. E.L.Raymond and D.A.Wells, "Effects of Aluminum Content and Heat Treatment on Gamma Prime Structure and Yield Strength of Inconel Nickel-Chromium Alloy 706", Superalloys -Processing (Columbus, $\mathrm{OH}$ Metals and Ceramics Information Center, 1972). N1-N21.

5. P.W.Schilke, J.J.Pepe, and R.C.Schwant, "Alloy 706 Metallurgy and Turbine Wheel Application", Superalloys 718,625,706 and Various Derivatives, ed., E.A.Loria (Pittsburgh, PA:TMS, 1994), 1-12.

6. Inconel 706 : Undated brochure obtained from The International Nickel Company, 1974

7. J.H.Moll, G.N.Maniar, and D.R.Muzyka, "The Microstructure of 706, a New Fe-Ni-Base Superalloy", Metallurgical Transactions, 2(1971), 2143-2151.

8. J.H.Moll, G.N.Maniar, and D.R.Muzyka, "Heat Treatment of 706 Alloy for Optimum $1200^{\circ} \mathrm{F}$ Stress-Rupture Properties", Metallurgical Transactions, 2(1971), 2153-2160.

9. L. Remy, J.Laniesse, and H.Aubert, "Precipitation Behavior and Creep Rupture of 706 Type Alloys", Materials Science and Engineering. 38(1979), 227-239. 
10. T.Takahashi et.al., "Effects of Gráin Boundary Precipitation on Creep Rupture Properties of Alloy 706 and 718 Turbine Disk Forgings", Superalloys 718, 625, 706 and Various Derivatives, ed, E.A.Loria (Pittsburgh, PA:TMS, 1994), 557-565

11. K.A.Heck, "The Time-Temperature-Transformation Behavior of Alloy 706", ibid., 393-404.

12. G.W.Kuhlman et.al., "Microstructure - Mechanical Properties Relationships in Inconel 706 Superally", ibid., 441 449.

13. R.Cozar and A.Pineau, "Morphology of $\gamma$ ' and $\gamma$ " Precipitates and Thermal Stability of Inconel 718 Type Alloys", Metallurgical Transactions, 4(1973), 47-59.

14. E.Andrieu, R.Cozar, and A.Pineau, "Effect of Environment and Microstructure on the High Temperature Behavior of Alloy 718", Superalloy 718 - Metallurgy and Applications, ed., E.A.Loria (Pittsburgh, PA:TMS, 1989), 241-256.

15. J.P.Collier, A.O.Selius, and J.K.Tien, "On Developing a Microstructurally and Thermally Stable Iron - Nickel Base Superalloy", Superalloys 1988, ed., D.N.Duhl et.al. (Warrendale, PA: The Metallurgical Society, 1988), 43-52.

16. E.Gou, F.Xu, and E.A.Loria, "Effect of Heat Treatment and Compositional Modification on Strengthening and Thermal Stability of Alloy 718", Superalloys 718, 625 and Various Derivatives, ed., E.A.Loria (Pittsburgh, PA:TMS, 1991), 389-396.
17. E.Gou, F.Xu, and E.A.Loria, "Comparison of $\gamma / \gamma$ " Precipitates and Mechanical Properties in Modified 718 Alloys", ibid., 397-408.

18. E.Andrieu et.al., "Influence of Compositional Modifications on Thermal Stability of Alloy 718", Superalloys 718, 625, 706 and Various Derivatives, ed., E.A.Loria (Pittsburgh, PA:TMS, 1994), 695-710.

19. X.Xie et.al., "Investigation on High Thermal Stability and Creep Resistant Modified Inconel 718 with Combined Precipitation of $\gamma$ "and $\gamma$ "', ibid., 711-720.

20. E.Gou, F.Xu, and E.A.Loria, "Further Studies on Thermal Stability of Modified 718 Alloys", ibid., 721-734.

21. A.K.Koul and R.Thamburaj, "Serrated Grain Boundary Formation Potential of Ni-Based Superalloys and its Implications", Metallurgical Transactions, 16A(1985), 17-26.

22. H.L.Danflou, M.Marty, and A.Walder, "Formation of Serrated Grain Boundaries and Their Effect on the Mechanical Properties in a $P / M$ Nickel base Superalloy", Superallys 1992, ed., S.D.Antolovich et.al. ( Warrendale, PA: TMS, 1992), 63-72.

23. S.Li et.al., "The Effect of $\delta$-Phase on Crack Propagation under Creep and Fatigue Conditions in Alloy 718", Superalloys 718, 625, 706 and Various Derivatives, ed., E.A.Loria (Pittsburgh, PA:TMS, 1994), 545-555. 